Article

\title{
Retinoic Acid, under Cerebrospinal Fluid Control, Induces Neurogenesis during Early Brain Development
}

\author{
M. Isabel Alonso ${ }^{1,2}$, Estela Carnicero ${ }^{1,2}$, Raquel Carretero ${ }^{1}$, Aníbal De la Mano ${ }^{1,2}$, \\ Jose Antonio Moro ${ }^{1,2}$, Francisco Lamus ${ }^{1}$, Cristina Martín ${ }^{1}$ and Angel Gato ${ }^{1,2, *}$
}

1 Departamento de Anatomía y Radiología, Facultad de Medicina, Universidad de Valladolid, C/ Ramón y Cajal 7, 47005 Valladolid, Spain; E-Mails: mialonso@med.uva.es (M.I.A.); ecarnice@ah.uva.es (E.C.); raquel.carretero@uva.es (R.C.); alamano@ah.uva.es (A.D.M.); moro@med.uva.es (J.A.M.); matutautara@yahoo.fr (F.L.); mariacristina.martin.1lorente@uva.es (C.M.)

2 Laboratorio de Desarrollo y Teratología del Sistema Nervioso, Instituto de Neurociencias de Castilla y León (INCYL), Universidad de Valladolid, 47005 Valladolid, Spain

* Author to whom correspondence should be addressed; E-Mail: gato@med.uva.es; Tel.: +34-983-186-398.

Received: 16 January 2014; in revised form: 6 March 2014 / Accepted: 18 March 2014 / Published: 8 April 2014

\begin{abstract}
One of the more intriguing subjects in neuroscience is how a precursor or stem cell is induced to differentiate into a neuron. Neurogenesis begins early in brain development and suddenly becomes a very intense process, which is related with the influence of Retinoic Acid. Here, using a biological test (F9-1.8 cells) in chick embryos, we show that "in vivo" embryonic cerebrospinal fluid regulates mesencephalic-rombencephalic Isthmic Retinoic Acid synthesis and this effect has a direct influence on mesencephalic neuroepithelial precursors, inducing a significant increase in neurogenesis. This effect is mediated by the Retinol Binding Protein present in the embryonic cerebrospinal fluid. The knowledge of embryonic neurogenetic stimulus could be useful in the control of adult brain neurogenesis.
\end{abstract}

Keywords: embryonic cerebrospinal fluid; retinoic acid; mesencephalic-rombencephalic isthmus; neuroepithelial precursors; neurogenesis 


\section{Introduction}

Embryonic Cerebrospinal Fluid (E-CSF) has been shown to play key functions in brain development at both embryonic and foetal stages, [1-8]. It influences the behavior of neuroepithelial cell precursors, regulating the survival, proliferation, and neural differentiation of neuroepithelial progenitor cells $[5,9,10]$, and also collaborates with the isthmic organizer in the regulation of mesencephalic gene expression [11]. Studies focusing on avian and mammal E-CSF proteomic composition reveal that this fluid includes a broad set of molecules, which might be responsible of their biological properties [12-15], and it has been suggested that there are specific molecules as FGF2 involved in specific cellular events, such neuroepithelial mitotic behavior [16].

Another key molecule in development, namely Retinoic Acid (RA), has been described as a powerful neurogenic agent in both embryo and adult neural progenitor cells [17-19]. RA synthesis requires the concurrence of a precursor molecule, all-trans retinol, a carrier molecule, Retinol Binding Protein (RBP), which also regulates the intake of retinol into the cells, and cells expressing the particular enzymes involved in transforming retinol to Retinoid Acid, namely Retinaldehyde Dehydrogenases (RALDHs) [20]. RA is a well-known morphogen that has a crucial impact on CNS development [21,22]. During early brain development in chick embryos the only RA metabolizing enzyme detected in the cephalic neuroepithelium, RALDH3, is located in the mesencephalic-rombencephalic isthmus (IsO), which is thought to be the RA source for brain neuroepithelium in chick embryos [23,24].

The precursor (all-trans retinol) and the carrier molecule (RBP) are present in the E-CSF from chick and rat embryos [13,14,24], which is in direct contact with the isthmic cells. At the same time, a direct involvement in neuroepithelial neurogenesis has been described for embryonic CSF both in chick [5] and rat embryos [25].

RA diffuses from the clusters of cells expressing RALDH enzymes, such as those forming some of the well-known organizing centers, to the target cells [23,26]. When RA is taken up by the target cells, it binds to specific nuclear receptors (RAR and RXR), regulating a series of genes involved in neural differentiation and patterning of anterior-posterior and dorsal-ventral axes [21,22,27-33].

Recently we showed, by means of an in vitro cellular culture system, that E-CSF activates neurogenesis in the mesencephalic neuroepithelial cells as a result of specific regulation of RBP-Retinol uptake in the IsO cells [34].

Here, using a similar experimental approach, we wish to ascertain if the same brain developmental mechanisms operate in live chick embryos.

\section{Experimental Section}

\subsection{Obtaining Embryos and Cerebrospinal Fluid}

Fertile chicken eggs were incubated at $38{ }^{\circ} \mathrm{C}$ in a humidified atmosphere to obtain chick embryos at the desired developmental stages according to Hamburger and Hamilton parameters [35]. Embryos were incubated to stage $\mathrm{HH} 24$ so as to procure E-CSF. After dissection of the embryos from the extra-embryonic membranes, E-CSF was aspirated as previously described [12]. To minimize protein degradation, E-CSF samples were kept at $4{ }^{\circ} \mathrm{C}$, aliquoted, lyophilized, and frozen at $-40{ }^{\circ} \mathrm{C}$, until they were required for use. 


\subsection{Culture of F9-1.8 Cell Line}

F9-1.8 cell line was maintained as previously described [36] on 1\% gelatine-coated (gelatin from porcine skin Type A from SIGMA) tissue culture flasks in Advanced-DMEM (Gibco, Gaithersburg, MD) supplemented with 7.5\% heat-inactivated FBS, $44 \mathrm{nM} \mathrm{NaHCO} 3$, and $4 \mu \mathrm{g} / \mathrm{mL}$ G418 (from Sigma). The cells were grown to $70 \%$, confluence. A pro-medium of $10^{7}$ cells/flask were re-suspended in $1 \mathrm{~mL}$ of medium and cultured overnight at $37{ }^{\circ} \mathrm{C}$ in a $5 \% \mathrm{CO} 2$ atmosphere for micro-injection. This cell line contains the Retinoic Acid Response Element (RARE) promoter coupled to the lacZ ( $\beta$-galactosidase) reporter gene.

\subsection{Micro-Injection of F.9-1.8 Cells "in Vivo"}

In order to test the influence of CSF on the Retinoic acid synthesis capacity of the IsO "in vivo", we used an experimental approach, based on the use of the cell line F9 1.8, which contains the Retinoic Acid Response Element (RARE) promoter coupled to the lacZ ( $\beta$ galactosidase) reporter gene, which will turn blue when activate. Briefly: 21 H.H. stage chick embryos were incubated and an opening made in the shell, exposed "in ovo". A volume of $10 \mu \mathrm{L}$ of an F.9-1.8 cellular suspension, as described before, was microinjected in the dorsal mesenchyme, deep in the mesencephalic-rombencephalic furrow, with a $50 \mu \mathrm{m}$ diameter Hamilton micro-syringe (Figure 1). Next, on each embryo we performed a second microinjection in the mesencephalic cavity, as we described before [16], of $40 \mu \mathrm{L}$ of an Anti Retinoic binding protein antibody at 1/100 dilution in PBS (Lab Vision Corporation, Neomarkers), or the same amount of heat-inactivated Retinol binding protein antibody. We used eight embryos for each experimental condition. We did not perform any other type of negative control in regards to the injection of F9 1.8 cells in other embryonic structures as it is extremely difficult to find places completely free of retinoic acid influence.

Subsequently, the egg shells were sealed and the eggs were reincubated for $24 \mathrm{~h}$ until reaching stage 24 H.H. The embryos were dissected form extra-embryonic membranes and fixed in $4 \%$ paraformaldehyde at room temperature for $3 \mathrm{~h}$. Finally, the X-GAL was developed following a standard protocol: the embryos were washed in PBS, followed by de-ionized water, and exposed to $20 \mathrm{mg} / \mathrm{mL}$ of X-gal solution diluted 1/50 in ferric solution (from Sigma) for $1 \mathrm{~h}$ at $37{ }^{\circ} \mathrm{C}$, as described by Sonneveld et al. [37]. The X-GAL positive cells inside the embryo were photographed with a binocular microscope.

\subsection{Neuroepithelial Cell Behavior Test}

In order to test the effect of the different experimental conditions on the behavior of the neuroepithelial cells, we selected the main parameters, cell survival, cell replication, and neurogenesis. 
Figure 1. Diagram of a saggital section of an early embryo cephalic end, showing the experimental approach used in this study. On the left, microinjection into the embryonic brain cavity of Retinol Binding Protein Antibody (aRBP) to block the Retinol uptake in mesencephalic-rombencephalic isthmus (IsO) RALDH positive cells. On the right, simultaneous microinjection F9-1.8 cells into the mesenchyme of the mesencephalic-rombencephalic furrow, as a sensitive test for Retinoic Acid activity.

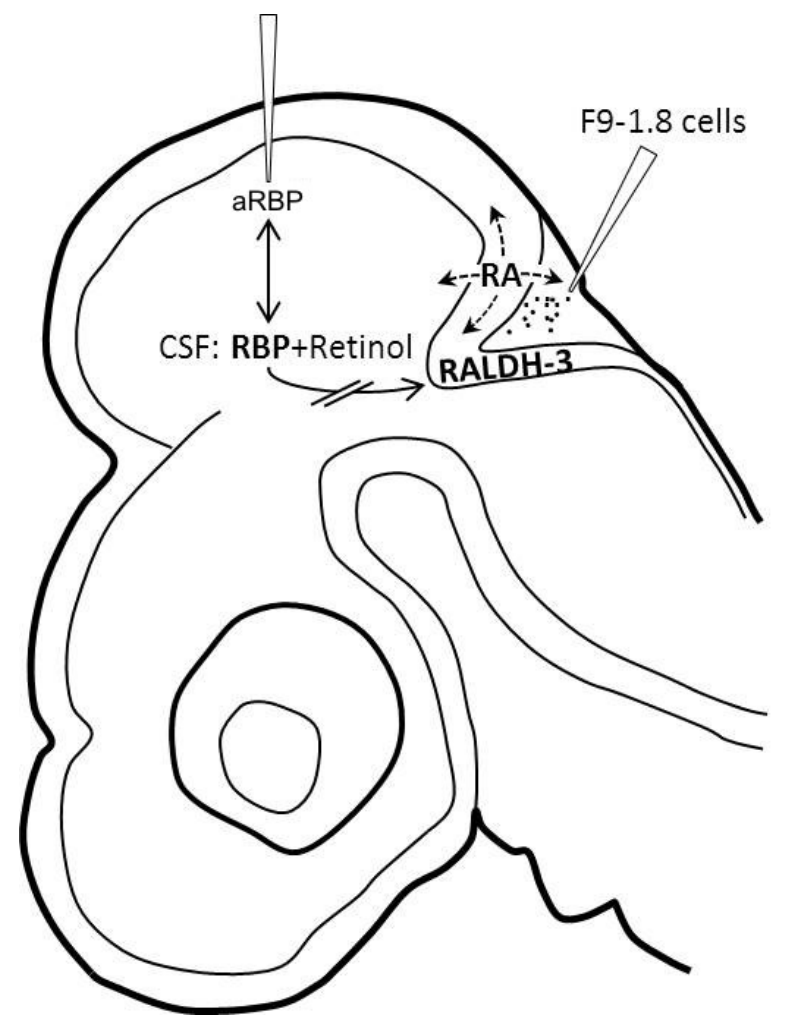

\subsubsection{Determination of BrdU}

Incorporation of BrdU into cell nuclei was performed by microinjecting $190 \mathrm{~nL}$ of a $5 \mu \mathrm{M}$ solution of BrdU in the outflow of the heart, exactly one hour before the end of the culture period; Immediately afterwards, the embryos were fixed in Carnoy for $20 \mathrm{~min}$, dehydrated, and embedded in paraffin. After transverse sectioning of the embryos, BrdU was detected with a monoclonal antibody to BrdU (Dako) at 1/100 dilution for $30 \mathrm{~min}$ and a secondary antibody with avidin-extravidin system conjugated to peroxidase (mouse anti-rabbit and extravidin from Sigma) was developed with DAB. We visualized and photographed the preparations using a Nikon microphot-FXA photomacroscope.

A quantitative analysis of nuclear BrdU incorporation was performed by counting the number of BrdU-positive nuclei in twenty microscopic fields of $1,400 \mu \mathrm{m}^{2}$ taken from four different embryos for each experimental condition. Both, the average of each condition, and the standard error, were plotted, and their significance was tested by a two-tailed Student's $t$ test.

\subsubsection{Neurogenesis}

We detected neuronal differentiation by $\beta 3$-tubulin expression. Embryonic sections from the embryos were blocked in 1\% BSA in PBS, then incubated with a monoclonal anti-tubulin antibody at 
1/500 (BAbCO), and, following extensive PBS washing, were incubated with an anti-mouse antibody conjugated to FITC at 1/64 (Sigma) for $1 \mathrm{~h}$ at room temperature. In order to facilitate identification of the $\beta 3$-tubulin-positive cells, we used single plane images obtained by confocal laser microscopy. A quantitative analysis of $\beta 3$-tubulin expressing cells was performed by counting the number of neuroepithelial cells with immunostained cytoplasm in 20 microscopic fields of $1,900 \mu \mathrm{m}^{2}$, from at least 4 different embryos. The average of each condition and the standard error were plotted, and their significance was tested by a two-tailed Student's $t$ test.

\subsubsection{TUNEL Assay}

In order to ascertain a potential influence of RA on cell survival, we assessed apoptosis by means of the TUNEL technique on paraffin sections from each experimental condition. Apoptotic cells were detected using the Apoptosis Detection System Fluorescein Kit (Promega), following the manufacturer's instructions.

Visualization was made with a confocal microscope (Zeiss LSM-310). We performed quantitative analysis by counting the number of stained nuclei of neuroepithelial cells in 10 microscopic fields of $1,900 \mu \mathrm{m}^{2}$, from at least four different samples. The average of each condition and the standard error were plotted and their significance was tested by a two-tailed Student's $t$ test.

\section{Results and Discussion}

First of all, we show the capacity of IsO to act as a physiological centre for synthesis and diffusion of RA during early brain development. We used F9-1.8 cells as a biological test for the presence of RA in live tissues, and in order to avoid the dispersion of these cells inside the brain cavity, we microinjected them deep in the cephalic mesenchyme in the dorsal region of the IsO, which has been described as the main location in the early chick embryonic brain that expresses RALDH and which consequently might produce RA. In all cases (eight embryos), after $24 \mathrm{~h}$, the F9-1.8 cells microinjected into the mesenchyme, close to the IsO, became blue (Figure 2A,C), showing the presence of retinoic acid activity in the extracellular space in this area. We previously showed the ability of the IsO cells to secrete Retinoic Acid to the extracellular space "in vitro", and our previous results strongly suggest that the final destination of this Retinoic Acid is the CSF, acting as a restricted diffusion channel to reach the neuroepithelial cells [34]. However, here we show that "in vivo" F9-1.8 cells microinjected close to but outside the neuroepithelilum are able to respond to RA secretion from the IsO cells, suggesting that, in vivo, the IsO cells produce an active form of Retinoic Acid which seems diffuse both peripherally and radially outside the IsO neuroepithelium, establishing an "area of influence" from an "organizing center". Consequently, RA could be included as a diffusible signal of IsO involved in early brain development [38]. Giving the local expression of RALDHs in cephalic developing structures [24,39] we cannot rule out the possibility that each area of RALDH expression (including those close to but outside the neuroepithelium such as retina and nasal placode) could exert its own influence on a part of the developing brain, and that this system evolves phylo and ontogenically [40], however this hypothesis needs experimental support. 
Figure 2. Photomicrographs of 23 H.H. stage chick embryos after microinjection of F9-1.8 cells in the mesencephalic-rombencephalic furrow delimited by a discontinuous line box in (A) and (B). After $24 \mathrm{~h}$ close to the IsO, the F9-1.8 microinjected cells develop a blue color (arrow heads in (A) and (C)) showing Retinoic Acid activity in this tissue. (C) and (D) show embryos with a similar experimental approach but with a simultaneous microinjection of Retinol Binding Protein antibody into the brain cavity. Note that the F9-1.8 cells do not develop a blue color, suggesting the blocking of retinoic acid binding activity in the area (scale bar in (A) and (B): $1 \mathrm{~mm}$; scale bar in (C) and (D): $100 \mu \mathrm{m})$.

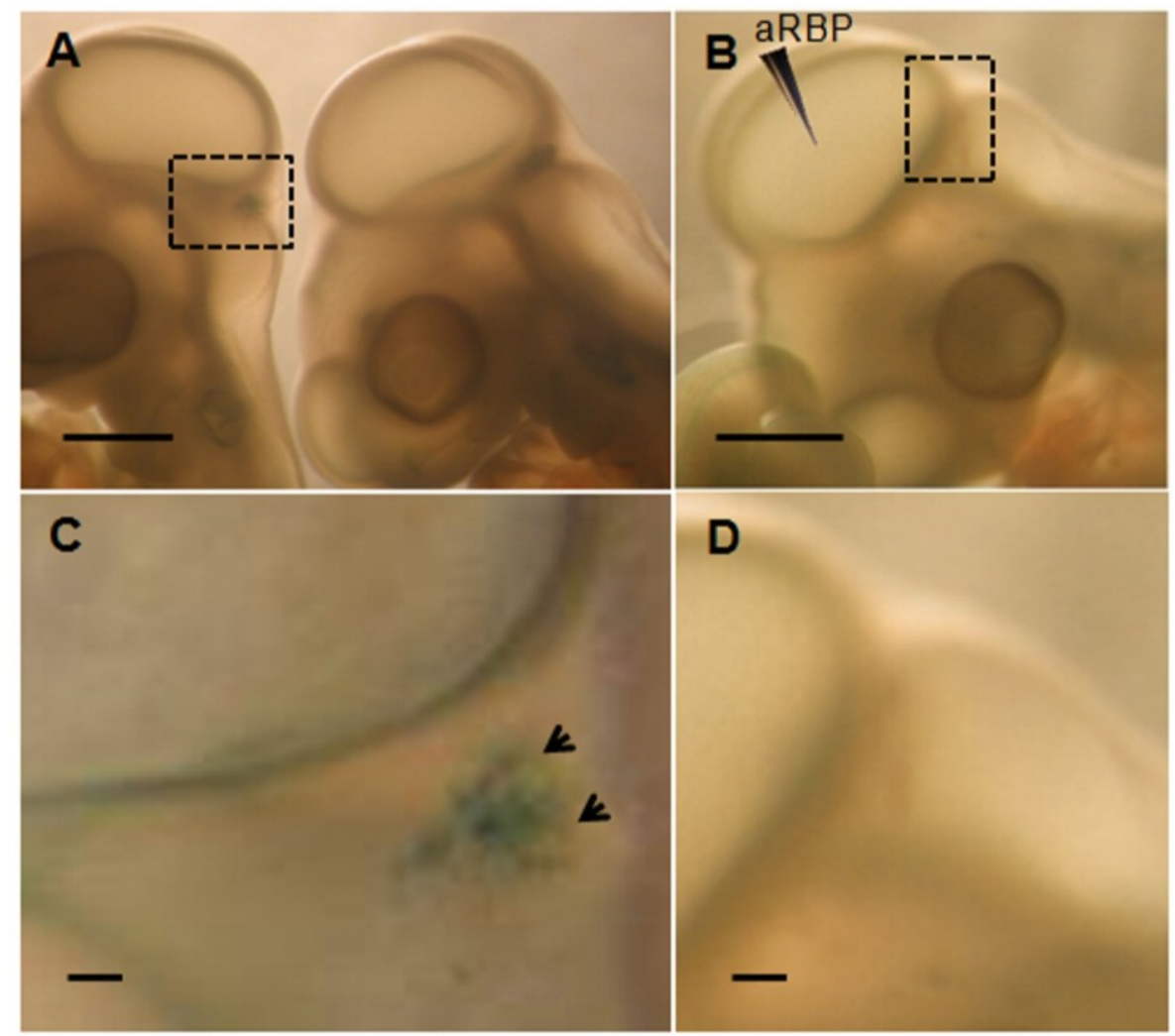

Secondly, we try to corroborate our hypothesis that, in vivo, the embryonic CSF was able to influence Retinoic Acid activity in the IsO, regulating the retinol uptake from RALDH positive IsO cells by the activity of the Retinol Binding Protein (RBP), both components present in embryonic CSF [24,34]. As before, we used an experimental approach based on the immunoblocking of RBP activity in the brain cavity of chick embryos, with a monoclonal antibody microinjected "in vivo", whilst at the same time performing a second microinjection of the F9-1.8 cells in the IsO mesenchyme to detect RA activity. It is relevant to note that in a previous study we showed that Inmunoglobulins such as FGF2 monoclonal antibody microinjected inside the cavity of chick embryo neural tube, are not able to cross the neuroepithelial barrier and remains inside the cavity [25], Consequently, the effect of antibody microinjection is attributable to specific immunoblocking of CSF components. As we show in Figure 2B,D, the immunoblocking of RBP activity in CSF was able to prevent the F9-1.8 cells microinjected in the IsO mesenchyme from becoming blue in color, which signifies no RA activity in the area. This effect was complete in six embryos, and in two the number of blue cells was greatly reduced compared to controls (no antiRBP antibody microinjected in brain cavity), probably due to a 
partial blocking of RBP activity. These results strongly suggest that "in vivo" control of Retinoic Acid synthesis by IsO cells depends on the CSF, which seems to be the main supply of the retinol for RALDH IsO cells, and also depends on the CSF RBP, which seems to be responsible for the intake of retinol inside these cells.

Figure 3. Evaluation of basic cellular behavior of mesencephalic precursor cells in control chick embryos $(\mathbf{A}, \mathbf{D}, \mathbf{G})$ or after Retinol Binding Protein immunoblocking in CSF (B,E,H). (A) and (B) show BrdU labeled nucleus used to evaluate cellular replication, of which values were plotted in $(\mathbf{C})$, with no significant differences between both groups. (D) and (E) show cytoplasm expression of $\beta 3$-Tubulin (Tuj1) used to evaluate early neurogenesis, of which values were plotted in $(\mathbf{F})$, and show a significant decrease in neurogenesis after RBP immunoblocking. (G) and $(\mathbf{H})$ show cellular apoptosis measured by the TUNEL technique and the results were plotted in (I) and a small but significant increase of RBP inmunoblocking (scale bar in (A) and (B): $50 \mu \mathrm{m}$; scale bar in (D-E) and (G-H): $100 \mu \mathrm{m}$ ).

CONTROL

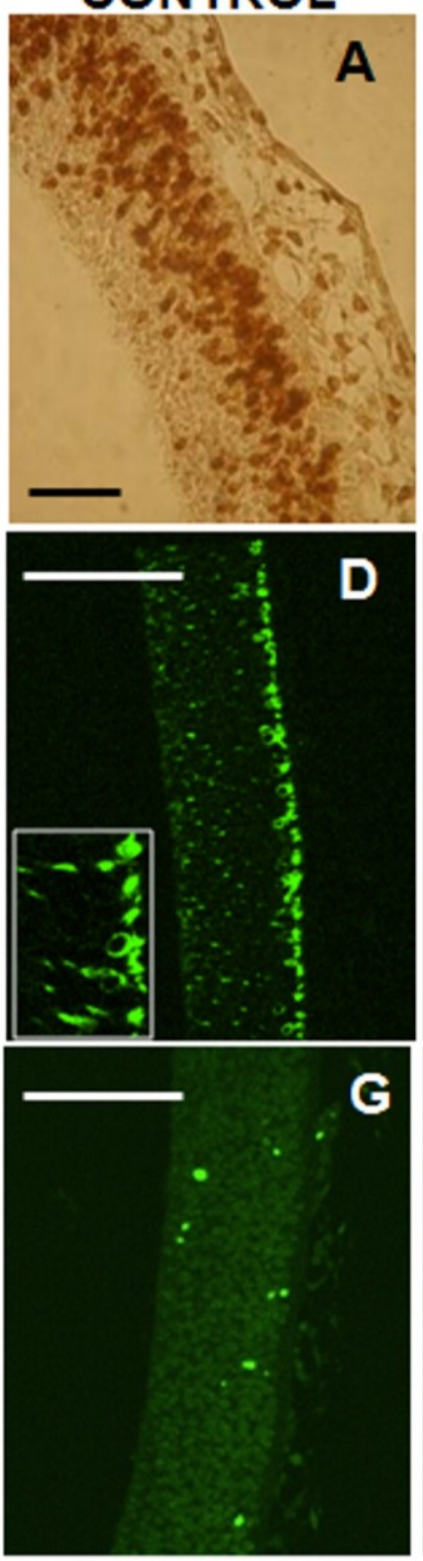

aRBP
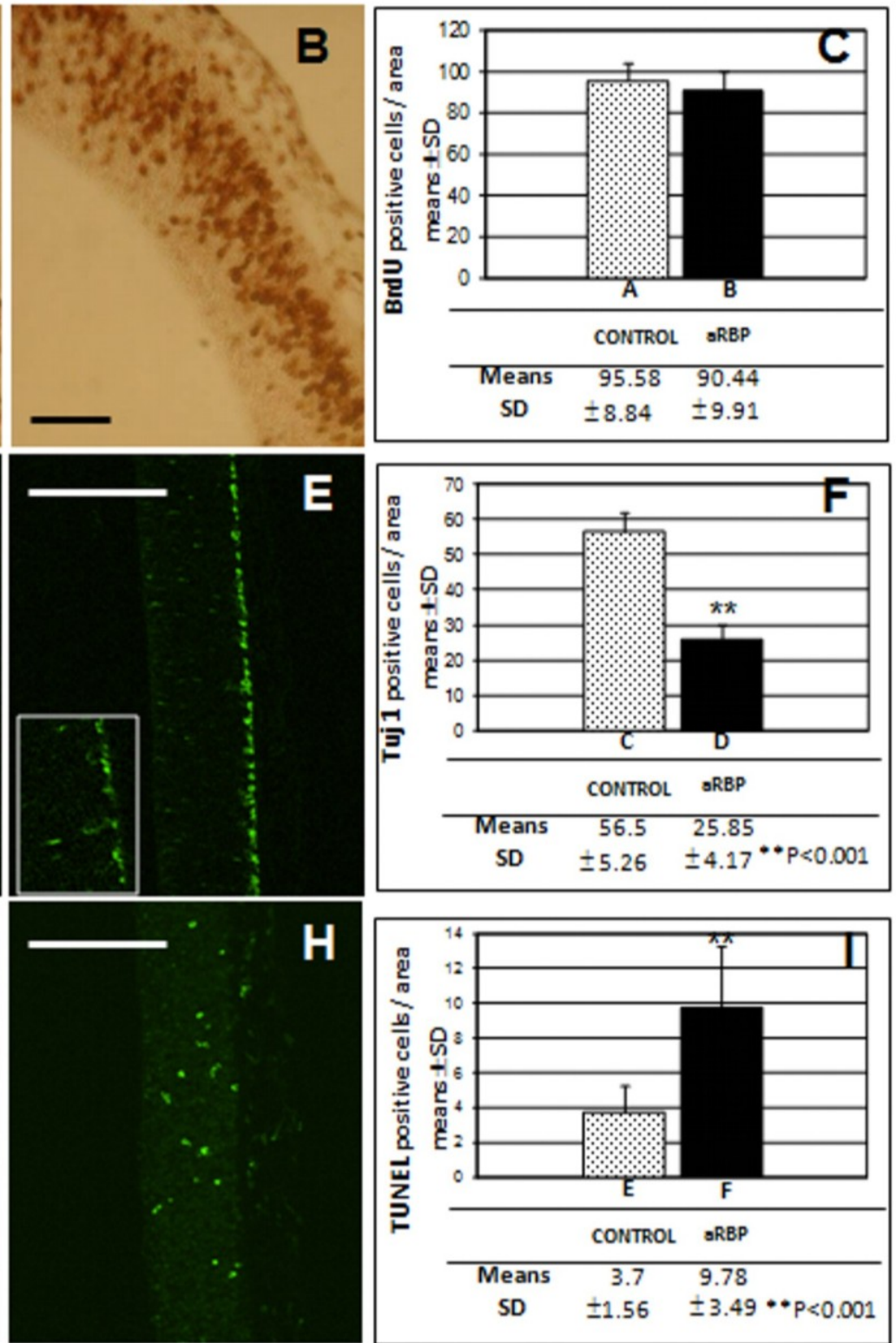
RA activity has been involved in the induction of neural differentiation during brain development [40,41] especially in the hindbrain derivatives; however, we previously described this relation in the mesencephalic neuroepithelium in an in vitro model. Thus, here we tested in vivo the neurogenic influence of the IsO as an RA source and mesencephalic neuroepithelial precursors as target cells.

In order to ascertain whether RA synthesis controlled by E-CSF is involved in mesencephalic neurogenesis in vivo, we studied the basic neuroepithelial precursor behavior in the mesencephalon of the chick embryos micro-injected with RBP antibody in the mesencephalic cavity. To test the replicative activity of the mesencephalic neuroepithelial cells, we previously incorporated BrdU into the cells for $1 \mathrm{~h}$ and evaluated the number of BrdU positive nucleus in the mesencephalic roof. As is shown in Figure 3A,B,C, the number of positive nuclei does not differ substantially in the RBP immunoblocked embryos with respect to the control ones, which suggests that RBP activity (and subsequently RA) is not related with cellular division in neuroepithelial precursors at this developmental stage. However, when we analyzed the number of $\beta 3$-Tubulin young neurons located in the basal side of the mesencephalic neuroepithelium (Figure 3D,E), we identified a clear decrease both in number and in the labeling intensity of $\beta 3$-tubulin (Tuj1) positive cells, which, however, maintain their basal location in the neuroepithelium. The data plotted in Figure 3F show a statistically significant decrease of more than $50 \%$ of $\beta 3$-Tubulin positive cells in RBP immunoblocked embryos compared with the control specimens.

In terms of the presence of apoptotic cells in the mesenchepalic neuroepithelium, made manifest by the TUNEL technique, a small number of positive cells are seen in the mesencephalic neuroepithelium of the control embryos; however, in RBP treated embryos there is a statistically significant increase in the number of apoptotic cells, more than double (Figure 3G,H,I). This effect could reflect the apoptosis of precursors unable to differentiate in neurons; however, we cannot rule out a direct influence of RA in neuronal survival.

\section{Conclusions}

Our results reinforce the hypothesis that, at the earliest stages of development, there is a narrow interrelation between neuroepithelial precursor cells and the CSF, which becomes an inner interneuroepithelial communication path. We also show that specific cellular events, such as neurogenesis, could be regulated by CSF in a non-direct way, such as the regulation of RA synthesis in the IsO. In the adult forebrain a relation has been described between neural precursor cells and Retinoic Acid expression [42], suggesting an ontogenically preserved role of Retinoic Acid in neurogenesis. Finally, we contribute to the knowledge of neural precursor regulatory mechanisms during development, which could be useful in the control of adult brain stem cell behavior taken in account that both (embryonic and adult) precursors seems to be the same cellular lineage [43].

\section{Acknowledgments}

The authors thank Mary Desmond for the helpful critical revision of the manuscript and Sagrario Callejo for technical support with confocal microscopy and to David Rixham for language translation assistance. He also thanks the Ministerio de Educación y Ciencia (BFU207/6516), and Junta de Castilla y León (Consejería de educación, GR195) for financial support of the research team. 


\section{Author Contributions}

J.A. Moro and A. de la Mano were responsible for microaspiration technique of CSF and for microinjection of F9 1.8 cells and RBP antibody in embryonic brain cavity. Both collaborate in the manuscript writing.

E. Carnicero and C. Martín were responsible for F9 1.8 cells culture and identification in embryonic tissues. Both work in manuscript writing.

M.I. Alonso, F. Lamus and R. Carretero were responsible for immunolabelling and TUNEL techniques, confocal images achievement and cellular counting. All three were involved in the results and discussion writing.

A. Gato was responsible for the experimental approach design, control and integration of the results and final version writing of the manuscript.

\section{Conflicts of Interest}

The authors declare no conflict of interest.

\section{References and Notes}

1. Checiu, I.; Prelipceanu, O.; Popescu, O. The role of the cerebrospinal fluid during embryonic development. A biochemical study. Morphol. Embryol. (Bucur.) 1984, 30, 243-250.

2. Desmond, M.E.; Jacobson, A.G. Embryonic brain enlargement requires cerebrospinal fluid pressure. Dev. Biol. 1977, 57, 188-198.

3. Dziegielewska, K.M.; Evans, C.A.; Lai, P.C.; Lorscheider, F.L.; Malinowska, D.H.; Møllgård, K.; Saunders, N.R. Proteins in cerebrospinal fluid and plasma of fetal rats during development. Dev. Biol. 1981, 83, 193-200.

4. Desmond, M.E.; Levitan, M.L. Brain expansion in the chick embryo initiated by experimentally produced occlusion of the spinal neurocoel. Anat. Rec. 2002, 268, 147-159.

5. Gato, A.; Moro, J.A.; Alonso, M.I.; Bueno, D.; De la Mano, A.; Martin, C. Embryonic cerebrospinal fluid regulates neuroepithelial survival, proliferation, and neurogenesis in chick embryos. Anat. Rec. A 2005, 284A, 475-484.

6. Miyan, J.A.; Nabiyouni, M.; Zendah, M. Development of the brain: A vital role for cerebrospinal fluid. Can. J. Physiol. Pharmacol. 2003, 81, 317-328.

7. Gato, A.; Desmond, M.E. Why the embryo still matters: CSF and the neuroepithelium as interdependent regulators of embryonic brain growth, morphogenesis and histiogenesis. Dev. Biol. 2009, 327, 263-272.

8. Zappaterra, M.W.; Lehtinen, M.K. The cerebrospinal fluid: Regulator of neurogenesis, behavior, and beyond. Cell. Mol. Life Sci. 2012, 69, 2863-2878.

9. Mashayekhi, F.; Draper, C.E.; Bannister, C.M.; Pourghasem, M.; Owen-Lynch, P.J.; Miyan, J.A. Deficient cortical development in the hydrocephalic Texas (H-Tx) rat: A role for CSF. Brain 2002, 125, 1859-1874. 
10. Owen-Lynch, P.J.; Draper, C.E.; Mashayekhi, F.; Bannister, C.M.; Miyan, J.A. Defective cell cycle control underlies abnormal cortical development in the hydrocephalic Texas rat. Brain 2003, 126, 623-631.

11. Parada, C.; Martín, C.; Alonso, M.I.; Moro, J.A.; Bueno, D.; Gato, A. Embryonic cerebrospinal fluid collaborates with the isthmic organizer to regulate mesencephalic gene expression. J. Neurosci. Res. 2005, 82, 333-345.

12. Gato, A.; Martin, P.; Alonso, M.I.; Martin, C.; Pulgar, M.A.; Moro, J.A. Analysis of cerebro-spinal fluid protein composition in early developmental stages in chick embryos. J. Exp. Zool. A 2004, 301A, 280-289.

13. Parada, C.; Gato, A.; Bueno, D. Mammalian embryonic cerebrospinal fluid proteome has greater apolipoprotein and enzyme pattern complexity than the avian proteome. J. Proteome Res. 2005, 4, 2420-2428.

14. Parada, C.; Gato, A.; Aparicio, M.; Bueno, D. Proteome analysis of chick embryonic cerebrospinal fluid. Proteomics 2006, 6, 312-320.

15. Zappaterra, M.D.; Lisgo, S.N.; Lindsay, S.; Gygi, S.P.; Walsh, C.A.; Ballif, B.A. A comparative proteomic analysis of human and rat embryonic cerebrospinal fluid. J. Proteome Res. 2007, 6, 3537-3548.

16. Martin, C.; Bueno, D.; Alonso, M.I.; Moro, J.A.; Callejo, S.; Parada, C.; Martin, P.; Carnicero, E.; Gato, A. FGF2 plays a key role in embryonic cerebrospinal fluid trophic properties over chick embryo neuroepithelial stem cells. Dev. Biol. 2006, 297, 402-416.

17. Goncalves, M.B.; Boyle, J.; Webber, D.J.; Hall, S.; Minger, S.L.; Corcoran, J.P. Timing of the retinoid-signalling pathway determines the expression of neuronal markers in neural progenitor cells. Dev. Biol. 2005, 278, 60-70.

18. Jacobs, S.; Lie, D.C.; DeCicco, K.L.; Shi, Y.; DeLuca, L.M.; Gage, F.H.; Evans, R.M. Retinoic acid is required early during adult neurogenesis in the dentate gyrus. Proc. Nat. Acad. Sci. USA 2006, 103, 3902-3907.

19. Wang, H.F.; Liu, F.C. Regulation of multiple dopamine signal transduction molecules by retinoids in the developing striatum. Neuroscience 2005, 134, 97-105.

20. Reijntjes, S.; Blentic, A.; Gale, E.; Maden, M. The control of morphogen signalling: regulation of the synthesis and catabolism of retinoic acid in the developing embryo. Dev. Biol. 2005, 285, 224-237.

21. Maden, M. Retinoic acid and limb regeneration-A personal view. Int. J. Dev. Biol. 2002, 46, 883-886.

22. McCaffery, P.; Drager, U.C. Regulation of retinoic acid signaling in the embryonic nervous system: a master differentiation factor. Cytokine Growth Factor Rev. 2000, 11, 233-249.

23. Blentic, A.; Gale, E.; Maden, M. Retinoic acid signalling centres in the avian embryo identified by sites of expression of synthesising and catabolising enzymes. Dev. Dyn. 2003, 227, 114-127.

24. Parada, C.; Gato, A.; Bueno, D. All-trans retinol and retinol-binding protein from embryonic cerebrospinal fluid exhibit dynamic behaviour during early central nervous system development. Neuroreport 2008, 19, 945-950. 
25. Martin, C.; Alonso, M.I.; Santiago, C.; Moro, J.A.; De la Mano, A.; Carretero, R.; Gato, A. Early embryonic brain development in rats requires the trophic influence of cerebrospinal fluid. Int. J. Dev. Neurosci. 2009, 27, 733-740.

26. Duester, G. Families of retinoid dehydrogenases regulating vitamin A function: Production of visual pigment and retinoic acid. Eur. J. Biochem. 2000, 267, 4315-4324.

27. Begemann, G.; Meyer, A. Hindbrain patterning revisited: Timing and effects of retinoic acid signalling. Bioessays 2001, 23, 981-986.

28. Clotman, F.; VanMaeleFabry, G.; Picard, J.J. Retinoic acid induces a tissue-specific deletion in the expression domain of Otx2. Neurotoxicol. Teratol. 1997, 19, 163-169.

29. Diez del Corral, R.; Storey, K.G. Markers in vertebrate neurogenesis. Nat. Rev. Neurosci. 2001, 2, 835-839.

30. Diez del Corral, R.; Storey, K.G. Opposing FGF and retinoid pathways: A signalling switch that controls differentiation and patterning onset in the extending vertebrate body axis. Bioessays 2004, 26, 857-869.

31. Kolm, P.J.; Apekin, V.; Sive, H. Xenopus hindbrain patterning requires retinoid signaling. Dev. Biol. 1997, 192, 1-16.

32. Kudoh, T.; Wilson, S.W.; Dawid, I.B. Distinct roles for Fgf, Wnt and retinoic acid in posteriorizing the neural ectoderm. Development 2002, 129, 4335-4346.

33. McCaffery, P.J.; Adams, J.; Maden, M.; Rosa-Molinar, E. Too much of a good thing: Retinoic acid as an endogenous regulator of neural differentiation and exogenous teratogen. Eur. J. Neurosci. 2003, 18, 457-472.

34. Alonso, M.I.; Martin, C.; Carnicero, E.; Bueno, D.; Gato, A. Cerebrospinal fluid control of neurogenesis induced by retinoic acid during early brain development. Dev. Dyn. 2011, 240, $1650-1659$.

35. Hamburger, V.; Hamilton, H.L. A series of normal stages in the development of the chick embryo. 1951. Dev. Dyn. 1992, 195, 231-272.

36. Schulz, W.A.; Gais, G. Constitutive c-myc expression enhances proliferation of differentiating F9 teratocarcinoma cells. Biochim. Biophys. Acta 1989, 1013, 125-132.

37. Sonneveld, E.; van den Brink, C.E.; van der Leede, B.J.; Maden, M.; van der Saag, P.T. Embryonal carcinoma cell lines stably transfected with mRARbeta2-lacZ: Sensitive system for measuring levels of active retinoids. Exp. Cell. Res. 1999, 250, 284-297.

38. Nakamura, H.; Watanabe, Y. Isthmus organizer and regionalization of the mesencephalon and metencephalon. Int. J. Dev. Biol. 2005, 49, 231-235.

39. Wilson, L.J.; Myat, A.; Sharma, A.; Maden, M.; Wingate, R.J. Retinoic acid is a potential dorsalising signal in the late embryonic chick hindbrain. BMC Dev. Biol. 2007, 7, doi:10.1186/1471-213x-7-138.

40. Chatzi, C.; Cunningham, T.J.; Duester, G. Investigation of retinoic acid function during embryonic brain development using retinaldehyde-rescued Rdh10 knockout mice. Dev. Dyn. 2013, 242, 1056-1065.

41. Maden, M. Retinoic acid in the development, regeneration and maintenance of the nervous system. Nat. Rev. Neurosci. 2007, 8, 755-765. 
42. Haskell, G.T.; LaMantia, A.S. Retinoic acid signaling identifies a distinct precursor population in the developing and adult forebrain. J. Neurosci. 2005, 25, 7636-7647.

43. Merkle, F.T.; Alvarez-Buylla, A. Neural stem cells in mammalian development. Curr. Opin. Cell. Biol. 2006, 18, 704-709.

(C) 2014 by the authors; licensee MDPI, Basel, Switzerland. This article is an open access article distributed under the terms and conditions of the Creative Commons Attribution license (http://creativecommons.org/licenses/by/3.0/). 